\title{
Los conflictos por el agua en territorio valenciano durante los siglos XIII-XIX: perspectiva general y factores agravantes
}

\author{
Tomás Peris-Albentosa \\ tomasperis@gmail.com
}

\begin{abstract}
Resumen. La conflictividad que afectó a las acequias valencianas ha sido contemplada desde diversos prismas. Jaubert de Passá (1844) o Giner Boira (1988) la ocultaron por considerarla una lacra descalificatoria. Arthur Maass o Elinor Ostrom, pese a dar gran importancia a este aspecto en su propuesta teórica, han tendido a soslayar los episodios más graves que enfrentaron a los usuarios de las aguas en el País Valenciano ${ }^{1}$. En la comunicación se defiende, en la línea de Calatayud y Garrido (2012: 95), que las organizaciones que gestionaron los usos del agua actuaron como instituciones funcionales en el manejo de un recurso natural especialmente difícil. Son, pues, entidades dignas del predicamento de que gozan, pese a que sufrieran episodios coyunturales muy violentos o etapas de gestión oligárquica extremamente corrupta. Entendemos que la existencia de incertidumbres y conflictos, en el contexto de una amplia autonomía local, estimuló la cooperación comunitaria. Las intensas tensiones vividas en determinados momentos actuaron como acicate que incitó acertadas mutaciones institucionales (evolución de las fórmulas participativas y cambios en la regulación normativa), que posibilitaron gestionar acertadamente el enorme potencial conflictivo ${ }^{2}$. Los colectivos implicados generaron mecanismos capaces de prevenir o limitar con rapidez los antagonismos desatados, permitiendo reconstruir y mantener amplios niveles de consenso.
\end{abstract}

Palabras clave: gestión del agua, conflictividad hidráulica, acequias, regadío, Valencia.

\begin{abstract}
Conflicts in the Valencian irrigation channels have been observed through different perspectives. Jaubert de Passá (1844) or Giner Boira (1988) hide them. Whereas Arthur Maass (2010: 72-82) or Elinor Ostrom (2011: 135-155) minimized them. This paper defends, following the works of Calatayud \& Garrido (2012: 95), that Valencian hydraulic institutions had to manage a very difficult natural resource. These institutions deserve their present prestige, but historically went through violent conflicts and stages of severe oligarchic control. The uncertainly and conflicts stimulated communitarian cooperation, boosting institutional changes (participative formulae and regulations changes) and increasing the capacity to control the enormous conflictive potential ${ }^{3}$. The collective institutions created suitable mechanism to control or limit antagonism and to build levels of consensus water users.
\end{abstract}

Keywords: water management, hydraulic conflicts, irrigation, channels, Valencia.

\section{Introducción}

La consideración teórica del conflicto ha sido muy diversa. Durante mucho tiempo se le contempló exclusivamente como una lacra negativa descalificatoria. Pero a partir de los ya clásicos estudios de L. Coser, Lederach, D. North o K.W. Kapp se comenzó a aceptar que la existencia de cierto nivel de rivalidad y de pugnas antagónicas (en determinado contexto institucional, en un ecosistema difícil, etc.) es capaz de llegar a actuar como un estímulo impulsor de acertadas evoluciones organizativas.

\footnotetext{
1 Maas\&Anderson, 2010: 72-82; Ostrom, 2011: 135-155, en especial 143. Dichos conflictos fueron bastante más frecuentes e intensos antes de que se generalizasen los grandes embalses reguladores a lo largo del siglo Xx. 2 Sostienen esta misma posición, con carácter general, Lana y Laborda (2013: 8-25) y Palerm (2000: 17-22). ${ }^{3}$ Lana y Laborda (2013: 8-25) and Palerm (2000: 17-22) also hold this position.
} 
En el caso de la conflictividad que afectó a los sistemas hidráulicos valencianos, la inmadurez de los estudios sobre los usos del agua en la perspectiva histórica, que se mantuvo hasta la década de 1980, contribuyó a que prevaleciera hasta entonces una visión sublimadora. Dicha perspectiva, originada en contextos de intensas transformaciones políticas y notables cambios legislativos ${ }^{4}$, insistía en la perfección del gobierno de las acequias y de la gestión hidráulica en ellas desarrollada. Como reacción a dicha tendencia, durante las últimas tres décadas ha ido adquiriendo fuerza cierta propensión conflictivista. Dicha corriente constituye una fecunda vía de análisis para ir desvelando como fue el funcionamiento cotidiano de las acequias valencianas, y ha contribuido a dar visibilidad a las pugnas por el agua, pero no está exenta de peligros. El mayor de ellos reside en considerar (como reacción a la anterior tendencia sublimadora y por contraste con un hidraulismo andalusí conceptuado como cooperativo, consensuado y poco conflictivo) que a lo largo de los cinco siglos de vigencia del sistema feudal se mantuvo una conflictividad hidráulica tan estructural como aguda.

Elinor Ostrom ofreció una visión todavía algo idealizada sobre el funcionamiento de los canales de riego valencianos, ya que reducía la conflictividad hidráulica a su mínima expresión como premisa que le permitía caracterizar a estas instituciones como paradigma de entidades exitosas en el manejo de recursos de uso comunitario (según esta prestigiosa autora, en las acequias valencianas «la violencia nunca se desencadenó de manera alarmante»; Ostrom, 2011: 143). A diferencia de este planteamiento, la presente comunicación insiste en dos aspectos fundamentales:

a) la necesidad de reconocer la existencia de múltiples manifestaciones conflictivas, incluyendo episodios coyunturales muy violentos;

b) la exigencia de contemplar el potencial positivo del conflicto, ya que fue capaz de estimular acertadas mutaciones institucionales que reforzaron la funcionalidad de las organizaciones que agrupaban a los regantes.

\section{El peligro de incurrir en planteamientos hiperconflictivistas}

Resulta muy fácil incurrir en propuestas que sobredimensionen la conflictividad relacionada con la gestión del recurso agua durante la etapa feudal, puesto que un conjunto de factores contribuye a otorgar credibilidad a esta perspectiva.

\subsection{La obvia trascendencia socioeconómica del agua}

Un primer elemento que actúa en el sentido apuntado es la relevancia alcanzada por el regadío. Disponer de agua significaba poder sembrar en el momento idóneo, estabilizar la producción interanual, multiplicar los rendimientos y optimizar el calendario agrícola. El riego otorgaba libertad para elegir cultivos, permitiendo crear un sistema agrario nuevo y optar por vías de desarrollo fuera del alcance de los secanos, lo que se traducía en un valor de la tierra regada habitualmente 5 veces mayor (en la Huerta, la hectárea regada se pagaba, en el siglo XIX, a 20.00045.000 reales mientras que la de secano ni siquiera llegaba a 4.000) $)^{5}$. Aparte de brillantes resultados económicos (según Jaubert, era «propiedad de los riegos, no limitar sus beneficios al terreno que bañan») $)^{6}$, las rotaciones intensivas daban «continua ocupación al labrador en todas las

\footnotetext{
${ }^{4}$ Borrull (1828) y Jaubert (1844) durante la Revolución Liberal de la primera mitad del siglo XIX, V. Fairén (1975) y V. Giner Boira (1988) en los años de agonía del Franquismo y Transición a un sistema democrático.

5 Peris, 1992: 26 y 191; Guillen, 1805: 189-192; Nadault, 1843, I: 1-2; II, 383, Peris, 2000, 52; Giménez, 2008: 156157; Peris, 2008: 132.

${ }^{6}$ Jaubert, 1844, I: 93-96.
} 
estaciones del año», haciéndole contraer el hábito al trabajo ${ }^{7}$. No extraña, pues, la concentración de esfuerzos productivos en el regadío y el abandono de los secanos que Cavanilles reseñó en tierras valencianas a final del $\mathrm{XVIII}^{8}$, ni que se produjesen graves conflictos en torno a la disputa de un agua de tanto en tanto insuficiente.

\subsection{Las facilidades para documentar enfrentamientos muy violentos}

Si a la trascendencia económica del agua unimos la complejidad para gestionar un recurso escaso e irregular, la idea de una exacerbada conflictividad hidráulica estructuralmente virulenta cobra fuerza. La facilidad para confeccionar un catálogo de conflictos acompañados de altas dosis de violencia parece otorgar crédito a una perspectiva en la que la excepción se transforma en norma, dando cuerpo a la tesis de pugnas estructurales y virulentas por el gobierno y administración de las aguas. Traeré a colación algunos casos, siguiendo una secuencia cronológica.

J. Castillo informa de graves episodios que enfrentaron a colectivos rurales en la Safor en 1376, 1386, 1401, 1416-1417, 1449 y 1459. En 1401, por ejemplo, los de Gandía rompieron el azud de Villalonga para que hasta sus campos llegase agua; los de Oliva repararon los destrozos y dejaron un grupo armado de 16 hombres para vigilarlo, pero fueron agredidos por más de 60 atacantes que volvieron a destruir el azud ${ }^{9}$. Conflictos furibundos resultaron frecuentes a comienzo del siglo XV. En el Camp de Llíria, el derecho de los mudéjares a regar en domingo «dio lugar a grandes y desastrosas desavenencias», hasta el extremo de ser incendiado Benisanó por los de Líria en 1408 (Madoz, 1982: voz Benisanó). En la Huerta de Valencia, los enfrentamientos alcanzaron gran intensidad en agosto de 1413, cuando la sequía era extrema: el Consell, «para que las cosechas [...] no se perdieran», autorizó formar una milicia integrada por «cien hombres a caballo, y $[\ldots]$ mil soldados de a pie, incluyendo arqueros y lanceros», dotada con «la artillería necesaria para destruir cualquier obstáculo que se encontrara en el río» (Glick, 1988: 200-210). Episodios violentos se repitieron en 1456-1757 en los espacios irrigados del litoral. Durante el verano de 1456, en Favara, la desobediencia masiva de los regantes de aguas arriba rompió la autoridad consensual, impidiendo a los guardas ejercer una supervisión efectiva (Glick, 1988: 8992, 120). En la misma coyuntura de aridez severa, el 18-VI-1457, el concejo alzireño ordenó a sus vecinos acudir en hueste armada a defender derechos hidráulicos amenazados por Sueca (Gual, 1979: 148-149).

En Sagunto, los antagonismos, canalizados jurídicamente hasta 1515, dieron paso a episodios de brutalidad alimentada por el resentimiento ocasionado por sentencias hidráulicas adversas. Los veredictos de la Audiencia, para frenar arbitrariedades del acequiero, generaron animosidad contra los mudéjares, de forma que cuando en 1521 la guerra de las Germanías afectaba a la comarca, los agermanados saguntinos saquearon Algimia y Alfara; en revancha, los moriscos de estas poblaciones «rompieron azudes y acequias que conducían el agua a Morvedre» (Iborra, 1981: 109). Dichos enfrentamientos se reiteraron a final del XVI (Madoz, 1982: voz Benisanó).

Las violencias hidráulicas se multiplicaron tras la expulsión morisca. En junio de 1613 se produjeron batallas en torno al azud de Alèdua: los del Marquesat destruyeron la presa sobre el río Magro y atacaron a los de Alginet cuando trataban de recomponerla, «tenint alsada una bandera, com si estigueren en frontera de enemichs» (Bosch, 2012: 160). También en Escalona la violencia fue un hecho cotidiano en las décadas de 1610-1620, cuando grupos armados de Carcaixent se

\footnotetext{
${ }^{7}$ Archivo Municipal Valencia, Cartilla Agricola, Agricultura, 14, nº 6.848, reg. 21.398, p. 16.

${ }^{8}$ Cavanilles, 1795, I: 183, 196, 208; 1797, II: 245-246, etc.

${ }^{9}$ Las ordenanzas municipales de Gandía de 1457 castigaban con amputar la mano derecha a quien dañase el azud o la acequia principal (Castillo, 1997: 68-70).
} 
apropiaban por la fuerza del agua ajena (Peris, 2003a: 100-101). En Orihuela se llegó a una corrupción oligárquica extrema, que estuvo a punto de provocar el colapso del sistema. Las Ordenanzas de 1625 explicitan que por la «injusta distribución de las aguas [...], permanecían incultas las tierras de muchos [...]. Los álveos o acequias no se mondaban ni se hacían las obras necesarias [...]. Los ricos eran exentos de contribución y no los pobres» (Nieto, 1980: 15-16). Las Ordenanzas de Mingot establecieron severas penas, pero tardaron en enderezar la situación, por lo que, durante más de veinte años, las sanciones se aplicaron a campesinos humildes mientras la élite local perpetraba abusos con total impunidad (debido a ello, las Cortes valencianas de 1645 redujeron las sanciones a una tercera parte; Guía, 1984: 287).

Los furores hidráulicos retomaron fuerza a final del Seiscientos y durante ciertas coyunturas del XVIII. Es probable que la rotura del embalse de Tibi, en 1697, se debiera a un sabotaje «explosión de pólvora»— instigado por los propietarios del agua vieja, cuyos intereses resultaban menoscabados por la regulación hídrica de la proyectada presa de acumulación (Alberola, 1994: 89-90). En Escalona, las pugnas fueron máximas entre 1696 y 1729, experimentándose «grandes disgustos, pendencias y muertes, que se originaron de quitarse unos a otros el agua, que sólo regavan primero los que tenían más industria y fuerza, los demás regantes con gran penalidad y tarde» (Peris, 2003a: 49). El funcionamiento oligárquico de los ayuntamientos borbónicos propició una gestión hidráulica menos equitativa y participativa de lo que suele suponerse, como demuestra la acequia de Alzira entre 1710 y 1767, donde se mantuvo una situación corrupta, resultado de "proponerse los rexidores a si mismos, haciendo como patrimonio suio estos empleos, para aprovecharse de los emolumentos que producían y dirigir las cosas en conveniencia y utilidad de sus haciendas propias y de sus parcialidades» (Peris, 1992: 277; 1995: 186). En la década de 1760 estallaron en el País Valenciano diversos motines originados por cuestiones de aguas ${ }^{10}$.

Tensiones extremas rebrotaron a final del XVIII y durante la primera mitad del Ochocientos. En 1828, los regantes de la Vega, tuvieron «que pedir auxilio de tropa al Capitán General para subir a imponer la norma [tandeo del Turia] a los Pueblos-Castillo» (Burriel, 1971: 155). Con todo, la furia más intensa y persistente se vivió en el Camp de Morvedre. Chabret informó que, a mitad del Ochocientos, «para impedir los atropellos y robos de agua durante el verano», hubo que situar «destacamentos de tropas en las casillas de las presas» (1888, 385-386). Marc Ferri, que ha profundizado en el análisis de esta convulsa etapa en la acequia Mayor de Sagunto (1830-1842), recalca que las resistencias comunitarias constituyeron una auténtica manifestación de protesta social contra las autoridades hidráulicas: se ignoraba la normativa impuesta coercitivamente, considerándose los usuarios de aguas arriba legitimados para cometer actos de desacato (Ferri, 2002, 81-104). Dicha situación se repitió en otras acequias cuando se experimentaba sequía extrema: en la Ribera, la resistencia de Sueca a obedecer la orden de las autoridades provinciales de ceder agua a Cullera, en 1851, obligó a destacar fuerzas militares y, en los tumultos subsiguientes, se ocasionaron diversas muertes (Calatayud, 2000: 287-288).

Podría pensarse que los episodios expuestos parecen otorgar credibilidad la versión de un experimentado burócrata especializado en cuestiones de aguas, Lorenzo Bachiller Rosillo, quien llegó a afirmar, en el tránsito al Ochocientos, que «en el Reino de Valencia [...] todos ven y experimentan que, no sólo por falta de agua, sino es por quién ha de regar antes, no solo riñen, sino es que se matan en todas partes» (cit. Giménez, 2008: 174). Sin embargo, debe advertirse que se trata de una versión tan exagerada como interesada, mediante la cual este jurista trataba de justificar el creciente intervencionismo de la corona, que él mismo aplicó con maneras autoritarias en la acequia Real del Júcar (Peris: 1992: 316-336).

${ }^{10}$ Mayans, 1976: 368; Peris, 1992: 164, 288-292; 1997: 46-47. 
La idea fundamental a retener es, pues, que la coerción extrema de una de las partes existió, pero fue una fórmula muy minoritaria de afrontar conflictos hidráulicos (concentrada fundamentalmente entre 1376 y 1460, 1609-1650, 1690-1735 así como las décadas de crisis del Antiguo Régimen y realización de la revolución liberal), que contrasta con las habituales evitación y consenso, aunque estas fórmulas resulten bastante invisibles a ojos de los historiadores (Maass\&Anderson, 2010: 400). Además, la violencia no constituía una auténtica vía de solución, sino que más bien fue una estrategia complementaria de presión (Román, 2000: 219). Pero la idea más importante a recalcar es que, si en lugar de focalizar la atención en las violencias hidráulicas, abrimos una panorámica general a los furores y crueldades que caracterizaron a la sociedad feudal, como las diversas modalidades de guerra privada ${ }^{11}$, cabe concluir que los altercados por aguas no resultaron especialmente intensos, sino todo lo contrario.

\subsection{Un marco historiográfico propicio a la perspectiva hiperconflictivista}

Si la facilidad para confeccionar un repertorio de disputas hidráulicas violentas en el muy largo plazo facilita incurrir en una percepción exageradamente conflictivista, también actúa en el mismo sentido el marco historiográfico predominante. En primer lugar, el estudio del agua ha sido una temática postergada en el conjunto de investigaciones históricas realizadas entre 1930 y 1980 (Peris, 1992, 27-28). Además, en el Ochocientos y durante la mayor parte del siglo xx, predominaron aquellas publicaciones que divulgaban mitos que recalcaban la perfección de la gestión desarrollada en los regadíos valencianos, tratando de sublimarla. Era una maniobra para mantener el status quo tradicional, amenazado por inminentes transformaciones políticas y frenar amenazadores cambios legislativos. F.X. Borrull recalcó que la distribución de las aguas en la Huerta estaba «tan bien dispuesta que a todos alcanza», excepto «en los tiempos de mayor sequedad» (1828: 13). Jaubert también se refirió a la perfección inmutable de los regadíos que rodeaban a la capital, donde «gobernantes espertos dirigen todos los intereses y necesidades»; y «jueces incorruptibles [...] arreglan, castigan o absuelven [...]. La cantidad de agua, administrada con una sabia economía, basta y aun escede las necesidades [...]; gefes libremente elegidos y [...] revocables rigen la acequia» (1844, I: 133, 389-391).

Si en el siglo XIX se expusieron tesis laudatorias para disipar peligros de cambio inherentes a la revolución liberal, V. Fairén y V. Giner hicieron lo propio al final del franquismo ${ }^{12}$. Tomaron como paradigma al Tribunal de las Aguas para recalcar supuestos aspectos extremamente positivos, tales como el carácter democrático del gobierno de las acequias; la ausencia de conflictos (ocultando la pluralidad de intereses en torno al agua y reconociendo únicamente meras infracciones, fruto de la desesperación individual); una dimensión judicial reducida a la justa aplicación de sanciones, etc. ${ }^{13}$. Obviamente, se trata de un discurso ideológico cuya pretensión era enmascarar el funcionamiento histórico, menos idílico de lo que estos juristas propusieron ${ }^{14}$.

\footnotetext{
11 Véase, para la Ribera del Júcar, Peris, 2002: 209-266.

12 Giner Boira, 1988: 27, 41-46, 54-55; Fairén, 1975. Giner llega a sostener que la intención de Jaime I sobre el gobierno de las aguas fue «conservar lo que ya era perfecto» (1988: 27).

${ }^{13}$ Un jurista tan brillante y bien informado del funcionamiento de las acequias valencianas como Cirilo Franquet se refería al Tribunal de las Aguas (Cort de la Seu), a mediados del XIX, como una institución muy positiva, que venía produciendo grandes beneficios a la agricultura de la Huerta; pero no porque su funcionamiento fuese óptimo sino porque resultaba preferible a otras posibles alternativas: "profundo conocimiento del pueblo que, a pesar de los graves defectos de la misma institución, ha temido más los peligros de su desaparición o reforma que los abusos y vejaciones que pueden cometerse a su sombra» (Franquet, 1864: 121-122).

14 Incluso autores tan brillantes como Maass u Ostrom incurren en cierta idealización de los sistemas de riego valencianos (Maass\&Anderson, 2010: 72-82; Ostrom, 2011: 135-155), que no se aviene con la realidad histórica de la etapa analizada, durante la cual la capacidad de regular el régimen de los cursos fluviales fue mínima.
} 
Pero, de cara a entender los peligros de incurrir en planteamientos hiperconflictivistas, la idea fundamental a retener es que cuando se recuperó el interés por efectuar un análisis riguroso de la gestión hidráulica, ya en las últimas décadas del siglo XX, se ha tendido a enfatizar el dramatismo de los antagonismos. Es, al menos en parte, una fórmula para marcar el contrapunto con la tendencia sublimadora hasta entonces dominante; pero que pierde de vista que las coyunturas de intensa conflictividad fueron situaciones extraordinarias dentro de la trayectoria multisecular analizada (Garrido, 2011: 28-29). El hecho que Glick otorgase relevancia a los conflictos, como fecunda vía para analizar el funcionamiento de las acequias medievales (Glick, 1988), ha contribuido a fomentar una visión conflictivista (Martínez, 1993). En el mismo sentido actúa la hegemonía historiográfica de las zonas más áridas del litoral mediterráneo, donde los niveles de conflictividad fueron -lógicamente- mayores. También la producción académica de medievalistas que aplican la propuesta teórico-metodológica de Miquel Barceló, quienes desarrollan su análisis a partir del supuesto de la dicotomía radical entre un hidraulismo andalusí, contemplado como participativo, cooperativo y consensuado entre grupos clánicos, frente a otro feudal, considerado expansivo, individualista y extremadamente conflictivo (Barceló, 1988, 1989; Peris, 2014 y 2014b).

\section{Hacia una conceptualización de los antagonismos: la multiplicidad de causas}

Un primer paso en el estudio de las pugnas hidráulicas consiste en crear categorías de conflictos. No se trata de confeccionar una clasificación taxonómica aséptica, sino de crear agrupaciones esclarecedoras que propicien extraer conclusiones. Por ejemplo, si distinguir entre conflictos internos y externos resulta provechoso es porque permite desvelar que el principal mecanismo para resolver pugnas intracomunitarias fue el consenso, mientras que para dilucidar rivalidades intercomunitarias resultó fundamental la acción mediadora de un poder político externo, en especial los tribunales del rey.

Otra consideración fundamental consiste en tener presente que las disputas por agua, fueron algo más que luchas por un caudal insuficiente, como demuestra la abundancia de casos en que se desperdició intencionadamente caudal para perjudicar a competidores económicos. Es lo que ocurría, por ejemplo, en la Safor a mediados del XVIII, cuando los vecinos de La Font regaban 140 hectáreas de algarrobos para damnificar a Oliva, privándola del agua (Memorial..., 1746: 53).

Un bloque de conflictos especialmente relevante lo constituían las dificultades para repartir aguas con equidad y sin ocasionar perjuicios a terceros. El riego forzado de tierras altas, incorporadas en fechas tardías, suscitó bastantes problemas. $\mathrm{Y}$ no son raras las disputas causadas por cuestiones de drenaje, que provocaban humedades nocivas. Así, la construcción de la acequia de Cullera en el siglo XV ocasionó daños en Corbera y Sueca (Peris, 1994: 22). Aunque existen noticias de perjuicios provocados por encharcamientos en todas las épocas ${ }^{15}$, resultan particularmente abundantes en el XVIII. Ignasi Mangue alude a las humedades sufridas en los extremales de la Huerta de Valencia (2000: 445). Incluso en las resecas tierras alicantinas, existían áreas concretas, como parte de la huerta oriolana, donde el principal problema lo constituía el exceso de humedad (Giménez, 2008: 376-377, 380-381). Los antagonismos originados por la disputa de un caudal exiguo se manifestaban en forma de oposición a nuevos proyectos hidráulicos que tomasen agua de un mismo curso fluvial, alterar un azud (Hermosilla, 2006), resistencia a incrementar el espacio irrigado o modificar partidores, así como desacatos a la distribución decretada por el acequiero en momentos de carestía ${ }^{16}$. La mayor conflictividad se experimentó en acequias compartidas por varios municipios: por ejemplo, en La Plana, las endémicas disputas entre Almazora y Castelló se solucionaron a final del XVIII mediante la

\footnotetext{
${ }^{15}$ Villa de Albalat..., pp. 84-85.

${ }^{16}$ Peris, 1997: 46; Iborra, 1981: 111-112; Calatayud, 2000: 284; Maass\&Anderson, 2010: 77-78.
} 
construcción de canales independientes para cada villa; lo mismo ocurrió entre Nules y Burriana hasta que en 1878 se autorizó a circular las aguas de cada término por acequias separadas (Guinot y Selma, 2002: 51-55).

Otro conjunto de antagonismos estuvo suscitado por el mantenimiento de la red de canales. Cuestión recurrente fue la existencia de tierras regadas ilegalmente, que no contribuían a conservar las infraestructuras, inconveniente que llegó a ser grave en la acequia Real de Alzira. Aunque los Capítulos Penales de 1596 habían establecido una sanción muy dura, 25 libras (el precio de una caballería), para quien regase sin tener sus tierras empadronadas, dicho problema afectaba al 20\% del espacio irrigado en 1728. Una asamblea de regantes, considerando que había más de 833 hectáreas que no pagaban cequiaje, para conseguir una recaudación justa y equitativa de la tasa con que financiar gastos, ordenó ejecutar «un sogueo general de todas las tierras». Sin embargo, cuarenta años después, el ingeniero Escofet reconocía que sólo se había realizado «un imperfecto sogueo [...], establezido [...] sobre la buena fe de las relaciones que han dado los mismos ynterezados regantes, en que se reconocen muchos fraudes de tierras que [...] ocultan por no pagar [...] gastos anuales de limpia y conservación de la azequias» (Peris, 1992: 195, 283). Numerosas cuestiones estuvieron relacionadas con la limpieza anual y obras de reparación, tareas instrumentalizadas para alterar la distribución de caudal. Así, los regantes de Almenara se sintieron agraviados, en 1667, por el «poco esmero con que hace Benifairó las mondas de las acequias, limpiando las que le interesan y dejando más enrunada la de Almenara»; por ello, solicitaron a los tribunales «licencia para limpiarse su acequia, cosa que Benifairó no consiente» (Cueco, 1965: 80-82, 92-93, 97-99).

También fueron relevantes las pugnas entre los diversos usos del agua: regadío, ganadería, pesca, transporte fluvial, molinería y servicios urbanos. Es bien conocida la relación conflictiva entre ganaderos y regantes, debido a los desperfectos que los animales producían en los cajeros de las acequias. Las disputas entre pescadores y regantes también fueron frecuentes e intensas en áreas de marjal, como los límites de la Albufera o el Bajo Segura. En el primer lago, los pescadores se quejaban de la suciedad que aportaba la acequia Mayor de Sueca. En 1646, debido a las protestas de los pescadores, el Real Patrimonio ordenó desviar al mar este canal, medida negativa para los labradores, «ya que impedía el desagüe de la Séquia dels Arbres», por lo que sus aguas inundaron diversas partidas. Las presiones de Sueca consiguieron que, en 1761, se aprobase «su vertido en la Albufera, a pesar de la oposición $\left[\ldots\right.$ de] pescadores $\left[\ldots\right.$ y] pueblos limítrofes al lago» ${ }^{17}$. Los conflictos entre regadío y pesca se intensificaron en el Bajo Segura durante el siglo XVIII, a medida que se transformaban antiguos terrenos palustres en campos regados (Giménez, 2008: 385-386, 377-379).

No parece que los conflictos entre molineros y regantes tuviesen la entidad que hasta hace poco se presuponía, gracias a la eficacia de mecanismos preventivos que dificultaban que un molino alterase la distribución de caudal entre los diversos brazales de un sistema hidráulico (Peris, 2012a; 2014b).

En cambio, los antagonismos que enfrentaban a transportistas fluviales con los intereses agrarios alcanzaron relevancia en las cuencas bajas del Turia y el Júcar. La navegación fluvial bloqueó durante los últimos siglos medievales el desarrollo del regadío en la Ribera Baja, ya que, para que el Júcar fuese navegable hasta Alzira, se prohibió construir azudes que derivasen agua hacia los campos $^{18}$. Los conflictos entre regantes y transportistas se intensificaron hasta obligar a establecer regulaciones en el XVIII, que no consiguieron atajar las disputas. Una cautela mitigadora consistía en inspeccionar cada azud antes y después del paso de los troncos, obligando a reparar los daños

${ }^{17}$ Calatayud y Furió, 1992: 300-306; Branchat, 1786, III: cap. VII, XLX; Sanchis Ibor, 2001: 110-144, 171-204. ${ }^{18}$ Calatayud, 1992: 301; Furió y Martínez, 1994: 577-582; Peris, 2003b: 54-55 y 195-199. 
detectados ${ }^{19}$. Borrull comentó la menguada eficacia de las reales órdenes de 1775-1776, que restringían el período de tránsito a los meses en que el riego era menos necesario (entre comienzos de octubre y final de abril), evitando el riesgo de ruptura del azud durante la fase de mayor aridez estival y urgencia por regar los campos. Dicha normativa dejó de cumplirse con frecuencia a causa que muchos troncos tenían como destino al Arsenal Real de Cartagena; también por la reiteración de hechos consumados, que obligaban a darles paso para evitar males mayores, antes de que se produjesen fuertes lluvias y el caudal del río crecía considerablemente ${ }^{20}$.

Los problemas de contaminación de aguas solían guardar relación con batanes textiles e instalaciones papeleras (Hermosilla, 2003: 322-323; Peris, 2014b), o prácticas de pesca que utilizaban plantas narcóticas. En 1789 se denunció que en la Vall de Segó, para coger peces «matapollan el agua», es decir, «echan en ella yerbas que [...] enborrachan al pescado», con el resultado que «este año ha muerto una caballería en Faura por haver bebido de agua infecta» (Cueco, 1965: 103-104). Dada la importancia de las acequias para abastecer a la población, siempre se puso una atención especial en evitar que los usuarios de aguas arriba ensuciasen la corriente, como muestra una sentencia que ordenó que «nadie pudiese en la acequia de Castellón lavar $[\ldots]$ cuadrúpedos, limpiar botas, ni echar perros muertos ni $[. .$.$] reses mortecinas o fétidas»$ (Giménez: 2008: 175).

Otro bloque de antagonismos, de una entidad tan ingente como obvia (de la que me ocuparé en otro artículo monográfico), eran las disputas entre colectivos de usuarios en torno al gobierno y gestión de cada sistema hidráulico: elaboración de normativa, concreción de la arquitectura institucional, nombramiento de oficiales, cobro de sanciones a los infractores, disputas de jurisdicción entre autoridades locales dotadas de competencias hidráulicas, oposición abierta de un grupo de usuarios a los oficiales del canal, disputas de atribuciones entre el señor y sus vasallos, etcétera.

Con todo, debe subrayarse que un último conjunto primordial de rivalidades estuvo relacionado con la competencia económica que experimentaban territorios colindantes o grupos socioprofesionales con intereses contrapuestos. Se trata de una causa habitualmente opaca, pero fundamental para poner de relieve que la conflictividad hidráulica tuvo un alcance mayor que la simple lucha por captar un caudal escaso. Ejemplo clarificador es la oposición al drenaje y desecación de espacios palustres, por parte de los beneficiarios de derechos comunitarios sobre zonas húmedas, derivados del modelo medieval de explotación del territorio (Lemeunier, 1997: 38). Nadault de Buffon recalcó con lucidez la resistencia genérica de quienes ya regaban a que otros territorios vecinos gozasen de semejante ventaja productiva, aunque ello no implicase ningún déficit de caudal que pudiese perjudicarles: «ceux qui, ayant leurs fiefs situés á proximité $d u$ canal, voyaient $[. .$.$] leurs besoins complètement satisfaits, n'avaient qu'un médiocre empressement de contribuer á$ mettre leurs voisins en possession des mêmes avantages» (1843, III: 40). Este tipo de antagonismos económicos, que suelen manifestarse como pugnas hidráulicas, se perciben con toda nitidez en la carta real del 9-XII-1589 que avisaba de la previsible oposición de la oligarquía aguateniente alicantina a dejar que se construyese el embalse de Tibi:

Pero como en el regimiento de la ciudad concurran algunos hombres de negocios que [...] su ganancia consiste en la esterilidad de la tierra, porque de ella nace [...] el comercio que hazen para bastecerla de otras partes, y otros, que son heredados en la Huerta [...], y por vender mejor sus frutos, habiendo poca agua, podría ser que, prefiriendo su comodidad particular al bien universal, lo quisiesen impedir (cit. Verdú, 1739: 40).

\footnotetext{
19 Peris, 1992: 101-116, 233-237; 2003: 133-134.

20 Sanchis y Piqueras, 2001: 203-204. V. Ferrer constata que esta problemática se intensificó durante los sucesivos años secos que abundaron entre 1840 y 1860 (1995: 273-275).
} 


\section{La incidencia de factores agravantes}

De cara a entender la trayectoria seguida por la conflictividad hidráulica, resulta conveniente establecer el peso específico de factores capaces de agravar o reducir los antagonismos. La principal causa fueron las intermitentes sequías y las coyunturas durante las cuales se materializaron cambios sociopolíticos drásticos. Otro factor estructural relevante fue la fragmentación jurisdiccional del territorio irrigado. También guarda relación directa con la intensidad de las pugnas el tipo de gestión realizada, bien por el desfase existente entre normativa $\mathrm{y}$ necesidades o debido a la puesta en marcha de relevantes innovaciones.

\subsection{La exacerbación de disputas durante las endémicas sequías}

La gestión hidráulica se caracterizó tanto por la falta de predictibilidad de la demanda de riego (sujeta a la irregularidad pluviométrica) como a la fuerte aleatoriedad de los caudales circulantes. Lógicamente, los conflictos se exacerbaban durante las peores sequías y amainaban durante las fases de lluvia copiosa. Abusos e ilegalidades se producían siempre; pero mientras se consentían durante aquellas etapas en que el caudal abundaba, se puso gran afán por detectarlas y atajarlas cuando llegaban años secos y el déficit hídrico se intensificaba. Es lo que ocurrió en la Huerta en torno a 1318-1321, cuando la sequía impulsó a realizar una inspección del Turia y los pleitos entre las acequias de la Vega y Montcada impelieron a la corona a decretar el tandeo del río, circunstancia que se repitió en 1358 cuando «con motivo de la grande sequedad que se experimentaba», Pedro II ordenó al Baile General realizar el prorrateo de aguas del Turia (Branchat, 1784, I: 326-327). Viejos abusos afloraban durante las peores sequías, como se documenta en la Comuna de l'Ènova en el Quinientos:

[...] en anys passats, ab la molta abundància de aygües, no se adonassen [...] dels abusos [...], y en après, sobrevenint sterilitat de aygua, axi per les seques com per haver fet moltes céquies los llauradors de Xàtiva [...], caygueren en lo conte que [... la] señora [...] de Manuel bavia fet llevar los dentells y sola [...], y examplats los caxers, y afondat lo sòl [...], de tal manera que [...] entrava grandíssima abundància de aygua [...], contra tot orde e justícia (Furió\&Martínez, 2000: 63-64).

En la cuenca del Palancia, la calma de etapas pluviosas daba paso a «un hervidero de denuncias, pleitos y cuestiones en cada época de sequía» (Iborra, 1981: 110-113). Mayans recalcó, a mitad del siglo XVIII, el nexo que vincula exacerbación de conflictos hidráulicos con años secos: «Si no se considerassen muchos años escasos de agua, no se pleitearía sobre ella, porque la avría suficiente para más de lo que es huerta pero, atendida esta frequente contingencia [...], deve adjudicarse el agua a las tierras que tienen derecho a ella» (Mayans, 1976: 333-336). La impredictiblidad del suministro, pauta común en ecosistemas mediterráneos, provocaba incertidumbre a la hora de tomar decisiones agrícolas y el subsiguiente aumento de tensión entre usuarios (Maass\&Anderson, 2010: 113, 389). Las sequías disparaban el potencial conflictivo latente (Nadault, 1843, I: 142). Por ejemplo, las resistencias de los regantes de La Plana contra usurpadores en Ribesalbes se agudizaron en los años secos, acabando con la permisividad manifestada durante lustros de aguas abundantes, como hicieron en 1798, cuando negaron el derecho de ocupación que esgrimían los constructores de azudes ilegales: «ni ha sido fácil denunciarlas, ni se han tenido en consideración quando ha havido abundancia de agua, pero quando se ha experimentado escasez resulta acreditado haver suvido [...] a reconocer el río y haver removido [...] embarazos para que descendiese toda el agua» (García Edo, 1994: 33-34). 


\subsection{La fragmentación jurisdiccional del territorio irrigado}

La etapa islámica se caracterizó por la unidad jurisdiccional del espacio beneficiado por cada sistema hidráulico, mientras que la sociedad feudal lo fragmentó en señoríos rivales, como Iborra Lerma comentó refiriéndose a Sagunto (1981: 78) y Furió y L.P. Martínez reiteran para la Ribera del Júcar, donde la segmentación señorial rompió la anterior cohesión andalusí, originando un aumento de la conflictividad y una creciente intervención de la corona (2000: 61-62). Las ventajas de la unidad jurisdiccional se constatan, por ejemplo, en la mayor probabilidad de obtener acuerdos que evitasen litigios en la Audiencia cuando las disputas enfrentaban a vasallos de un mismo señor. Así, Benaguacil y Pobla de Vallbona cerraron disputas con un pacto propiciado por el duque de Segorbe, señor de ambas poblaciones (Llavata, 1981: 551). El mismo efecto balsámico se detecta entre Valencia y los pueblos-castillo, hasta el punto que, para evitar disputas con usuarios de aguas arriba, la capital llegó a comprar estos señoríos ribereños del Turia ${ }^{21}$.

Simples cambios en la titularidad de señoríos vecinos resultan claves para entender el incremento de la conflictividad por aguas. Ejemplo ilustrativo es la acequia de Alèdua en el XVI, cuando coincidió el interés por aumentar el regadío con la implicación de dos de los más poderosos linajes del reino: Joan Borja compró la Foia de Llombai en 1494 y Jeroni Cabanyelles hizo lo mismo con Alginet en 1509. El conflicto de intereses entre ambas influyentes estirpes, inmersas en una competición para multiplicar rentas mediante la expansión del regadío (que no podían dar su brazo a torcer si querían mantener su reputación), trajo consigo un notable aumento de la conflictividad hidráulica experimentada en la zona durante el Quinientos (Bosch: 2012: 158-159). Otra evidencia que muestra la agudización de las tensiones a causa de la fragmentación jurisdiccional del territorio irrigado es la mayor conflictividad que se constata en aquellas acequias cuyas aguas eran compartidas por diversos municipios, como ocurría, por ejemplo, entre Villareal y Burriana en el siglo XV (Román, 2000: 203-205) o entre Benaguacil y la Pobla de Vallbona durante el XVII (Hermosilla y Morales, 1993: 65-66). Para reducir tensiones, se llegaron a realizar onerosas inversiones en infraestructuras para conseguir que el agua circulase por acequias separadas, como ya efectuaron Almoines y Bellreguart en 1494 (Castillo, 1997: 85-91) o Castellón-Almazora en 1787.

\subsection{Las deficiencias en la gestión hidráulica}

La indefinición de la normativa fomentó todo tipo de abusos, cometidos gracias a la capacidad coercitiva de los poderosos, recrudeciendo la conflictividad en torno al uso de las aguas. La fragmentación de poderes característica del sistema feudal propició, durante los primeros tiempos de su vigencia, confusión normativa y solapamientos de potestades hidráulicas. Para soslayar estos efectos adversos, durante los últimos siglos medievales se mantuvo un proceso de normativización legislativa -integrada por acuerdos internos, sentencias judiciales y privilegios reales- que recogía diversos elementos de la tradición andalusí (Castillo, 1997: 100-103).

Una vez corregida esta indefinición, si los preceptos que guiaban el uso de las aguas no llegaban a ser considerados justos y equitativos por los implicados, su grado de cumplimiento era bajo, dado que los perjudicados no se sentían comprometidos en su observancia y la vigilancia institucional permanente resultaba inviable. Es por ello que en las acequias valencianas se constata la búsqueda de equidad como objetivo prioritario, idea ya apuntada por Arthur Maass y que ha sido reformulada por Ostrom (Maass y Anderson, 2010: 73; Ostrom, 2011: 170-171; Garrido, 2011: 20). Glick recoge como la percepción de injusticia de los usuarios inferiores de Montcada, en el año 1425, les incitó a abandonar el recurso a las instituciones internas como vía de resolución de conflictos (1988: 123).

${ }^{21}$ La posterior enajenación de estos territorios reactivó la conflictividad hidráulica (Burriel, 1971: 153-154). 
Las novedades impuestas sin el consenso de los implicados, mediante la injerencia de poderes políticos, también incidía en forma de crisis de legitimidad de los códigos y oficiales de riego, como ocurrió en el tránsito del XVIII al Ochocientos, dentro del proceso de deslegitimación general que afectó al conjunto de instituciones tradicionales del Antiguo Régimen (Ferri, 1997: 79).

La gestión hidráulica se complicaba por las dificultades para establecer y mantener mecanismos operativos sencillos que distribuyesen el agua con equidad, debido al régimen tan irregular de las precipitaciones y del caudal de los ríos valencianos. En el norte de Italia, la regularidad de los cursos fluviales permitió funcionar, desde el siglo XVII, módulos hidráulicos que dejaban pasar automáticamente- el caudal exacto otorgado a cada conjunto de usuarios. En cambio, esta solución técnica no era viable en el litoral mediterráneo peninsular, donde los estiajes obligaron a aplicar reglamentos muy complejos y necesariamente flexibles, así como mantener una vigilancia constante, a fin de atajar abusos y distribuir el menguante caudal veraniego de manera proporcional entre quienes compartían el derecho al agua ${ }^{22}$.

La graduación de las multas a la entidad de las infracciones resultó crucial para mantener baja la conflictividad (Ostrom, 2011: 173-181; Garrido, 2011: 29-30). Jaubert ya atisbó este nexo, atribuyendo la mayor tensión experimentada en las acequias de la Huerta a comienzos del XIX a la escasa eficacia disuasoria de las sanciones. Refiriéndose a Quart, comentó los «abusos que resultan de la insuficiencia de las multas»; también informó que en Mislata, «en tiempo de sequía, trae ventaja al usurpador del agua el pagar la pena, porque espera sacar mayor producto de la tierra con el riego que le da que lo que sube la multa» (1844, I: 393-398). Los coetáneos atribuían las graves tensiones experimentadas en Sagunto en 1848 a la profusión de riegos clandestinos, puesto que «con el desembolso de dos o tres mil reales logran cosechas en valor de dos o tres mil duros» (Ferri, 2002: 88).

El óptimo funcionamiento de los sistemas requería que la justicia de aguas fuese equitativa y rápida, debido a la urgencia por corregir abusos y regar cosechas necesitadas. Los pleitos enquistados derivaban en aumento de la tensión entre usuarios y desafíos a los oficiales de la acequia. Había, pues, que dar respuestas institucionales adecuadas, en especial cuando se producía una expansión del espacio irrigado, legalizando usurpaciones u otorgando plenos derechos a usuarios esporádicos que antes únicamente disponían de dotaciones precarias.

Las obras para reparar desperfectos ocasionados en la red de canales por inundaciones también generaban aumentos de conflictividad, tensiones debidas tanto a disensiones sobre la recaudación para pagar los gastos como a aspectos técnicos de las obras, que podían alterar el reparto de caudal o modificar los flujos del agua durante las riadas. Es lo que ocurrió, por ejemplo, con las inundaciones del Serpis durante el Cuatrocientos (Castillo, 1997: 67), con las riadas del Júcar a lo largo de los siglos XVI-XVIII ${ }^{23}$ o las del Vinalopó durante el Setecientos (Pérez Medina, 1997b: 60).

\subsection{Los efectos negativos de coyunturas bélicas e inestabilidades políticas}

Cualquier circunstancia que provocase confusión y caos, en especial guerras y cambios radicales en el sistema político, era caldo de cultivo propicio para que la conflictividad hidráulica se disparase de forma exponencial.

Uno de los factores externos con mayor potencial para exacerbar las pugnas en torno al agua era experimentar importantes cambios sociopolíticos, en especial guerras y cambios políticos

\footnotetext{
${ }^{22}$ Nadault, 1843, I: 58, 64, 112-118; II: 71, 101, 116-117, 197, 382-384.

${ }^{23}$ Vercher, 2005: 421-426; Giner Perepérez, 1992: 357-358; Peris, 2001: 99-120; Peris, 2003: 44-57.
} 
drásticos. Una parte considerable de los conflictos hidráulicos que se constatan tras la conquista del siglo XIII se debió a la inestabilidad suscitada por la implantación del sistema feudal ${ }^{24}$. Aparte de las grandes mutaciones generales (conquista, expulsión de los moriscos, Nueva Planta, revolución liberal, etc.), también los reajustes focalizados afectaron a la conflictividad hidráulica en la zona implicada. Por ejemplo, los cambios en el equilibrio político experimentados en las Valls del Vinalopó a partir de 1392 (disputas de poder entre diversos señores feudales) intensificaron las pugnas hidráulicas en esta cuenca durante algunas décadas (Pérez Medina, 2005: 448).

Es bien conocido el aumento de conflictos hidráulicos experimentado tras la expulsión morisca de 1609, circunstancia que se relaciona tanto con la inestabilidad inherente al proceso de repoblación como con el reajuste efectuado en las relaciones señores/vasallos. Esta circunstancia se constata, por ejemplo, en la comarca de la Costera: la frustración de las aspiraciones de l'Alcúdia y Canals a incrementar su caudal provocó un aumento de fraudes, ya que la concordia de 1613 consagró la tradicional división del río en 24 filas, lo que suponía la imposibilidad de Canals y l'Alcúdia de adquirir más caudal, circunstancia que provocó un incremento de fraudes en las acequias que suministraban agua a Xàtiva (Hermosilla, 2003: 46-48).

Especialmente elocuentes resultan la guerra de Sucesión a comienzos del XVIII y la lucha contra los ejércitos napoleónicos o las sucesivas guerras Carlistas en el XIX. Los efectos de la guerra de Sucesión (1705-1707) se dejaron sentir en muchos canales valencianos. Así, en la acequia de Alèdua, la política de confiscación y secuestro de bienes de nobles austracistas, que afectó al señor de Alginet, intentó ser aprovechada por el marqués de Llombai para arrebatarle derechos hidráulicos (Bosch, 2012: 160). En la acequia de Escalona, la represión borbónica originó usurpaciones de aguas por parte del señor de Cárcer, que únicamente pudieron corregirse a partir de 1765 (Peris: 2003a: 167). El caos bélico y la extrema inestabilidad política de la primera mitad del Ochocientos provocaron innumerables abusos por parte de usuarios de aguas arriba -sobirans-, como se constata en la zona de Sagunto (Chabret, 1888: 385-386).

\section{La multiplicidad de fórmulas aplicadas para limitar desavenencias hidráulicas}

Estudios genéricos sobre resolución de conflictos enseñan que en cualquier ámbito donde se produzcan disensiones coexisten múltiples estrategias para canalizar las pugnas. Estas prácticas comprenden desde la frecuente evitación, modalidades de coerción, aplicar normativa consensuada, fórmulas de negociación basadas en la confianza mutua y la voluntad de evitar males mayores, el recurso a la vía judicial y, finalmente, la obtención del favor político (Maass aludió a cuatro fórmulas: evitación, coerción, negociación e intervención de un tercero (que incluye mediación, arbitraje, resolución judicial y disposiciones legislativas; 2010: 396-400).

Al estudiar la conflictividad hidráulica, resulta fundamental no dejar de lado ni la evitación por parte de los elementos más débiles involucrados, ni el recurso a la vía política, mediante el cual se trataba que la capacidad legislativa y arbitral de corona o de los señores feudales -según casosdesequilibrara la balanza en favor de una de las partes enfrentadas. Por otro lado, resulta tan incorrecto focalizar excesivamente la atención en los mecanismos coercitivos basados en el uso de la fuerza bruta y la aplicación de violencias disuasorias como tratar de ocultar la existencia de este tipo de actuaciones. Infinidad de flagrantes injusticias perduraron durante generaciones debido a la impotencia de quienes las sufrían, y sólo una parte derivaron en conflagraciones violentas o furores que obligaron a reajustar los frágiles equilibrios que vinculaban a los usuarios

\footnotetext{
24 Peris, 2014a. En la cuenca del Mijares, los señores de la zona pactaron seis concordias entre 1275 y 1355 , para frenar la indefinición legal y el aumento de conflictos que se experimentaba (Jaubert, 1844, I: 97-98).
} 
del agua, modificando normas, pactando concordias, impulsando sentencias o promulgando decretos para atenuar los desajustes más peligrosos.

También resulta fundamental no contemplar a los sistemas hidráulicos como entidades herméticas. Ningún colectivo de usuarios desarrolló una gestión totalmente autónoma, sin ningún tipo de articulación con los poderes políticos externos, municipios, señores y corona (Peris, 2014a, 2014b). Los mecanismos internos para resolver conflictos (fórmulas participativas para desarrollar consensos y justicia local en primera instancia basada en prácticas consuetudinarias o normas pactadas) son esenciales para entender la dinámica experimentada en las acequias valencianas. Sin embargo, hay que tener presente la potencia institucional de decisiones externas, tales como privilegios, decretos reales, sentencias judiciales, etc., capaces de llegar a condicionar en algunos aspectos la trayectoria interna seguida en cada sistema hidráulico.

En un balance sobre la cuestión, hay que concluir lo siguiente. Primero, que apenas se ha prestado atención a los mecanismos de evitación, difíciles de documentar, pero imprescindibles para no distorsionar el análisis. En segundo lugar, la historiografía ha minusvalorado la capacidad de intervención de la corona, en especial en lo que se refiere a su facultad legislativa sobre los ríos y grandes acequias fluviales, puesto que los privilegios reales condicionaron muchos aspectos de la gestión desarrollada en el interior de cada macrosistema. Tercero, que las coerciones extremas y los episodios cargados de gran violencia fueron situaciones espectaculares, pero que deben ser valoradas como poco significativas en un balance de muy largo plazo. Además, conocemos mejor lo proclamado por la normativa de los códigos que su praxis cotidiana. También debe ponderarse la entidad primordial de las soluciones consensuadas por los colectivos de usuarios implicados, que en infinidad de ocasiones hizo innecesario acudir a la vía judicial y en otros casos precipitó la resolución de los litigios en forma de $\operatorname{concordias}^{25}$. En sexto lugar, debe recalcarse que el aumento del número de pleitos documentados a lo largo del Antiguo Régimen provoca la falsa impresión que la conflictividad hidráulica se intensificó notablemente entre los siglos XVI y $\mathrm{XVIII}^{26}$. Por último, debemos subrayar que la vía política, la gracia del rey, ejercida a favor de instituciones o personajes poderosos, fue un mecanismo tan relevante como dejado de lado en los análisis sobre el gobierno y gestión de las acequias.

\section{Conclusión: hacia un nuevo marco teórico-metodológico para estudiar la conflictividad hidráulica durante la etapa feudal}

Las organizaciones de regantes nunca fueron entidades herméticas, por lo que los conflictos por el agua experimentados entre los siglos XIII y XVIII deben ser contemplados como parte del conjunto de tensiones y pugnas generales originada por la disputa del poder y las riquezas en el contexto del sistema feudal. Una premisa básica en el análisis consiste en considerar que las manifestaciones de antagonismos hidráulicos formaron parte del conjunto de rivalidades a que se vio sujeto el mundo rural, de manera que no pueden considerarse ni como una conflictividad aislada (desligada de otras modalidades de disputa de intereses) ni como porfías especialmente exacerbadas. Por ejemplo, las luchas por el agua en la Safor del Cuatrocientos, anteriormente descritas, formaban parte de las contiendas que opusieron a nobles y comunidades rurales, pulso mediante el cual el duque de Gandía y el señor de Oliva trataron de imponer su preponderancia en la comarca (Castillo, 1997: 99). También las brutales agresiones perpetradas por regantes saguntinos contra usuarios mudéjares de las aguas del Palancia durante las Germanías deben

\footnotetext{
${ }^{25}$ En las acequias valencianas se propiciaron soluciones internas, que forzaban a acatar normas pactadas, y se limitó el recurso a los tribunales (Jaubert, 1844, I: 207).

${ }^{26} \mathrm{La}$ mayoría de apelaciones elevadas ante los tribunales del rey fueron instadas por usuarios de aguas abajo con escaso poder coercitivo; pero esta vía tenía graves inconvenientes, como su lentitud y onerosidad (Cueco, 1965: 47, $70)$.
} 
enmarcarse en el contexto de disputas entre una importante villa de realengo y diversos señoríos vecinos (Iborra, 1981, 109).

El carácter comunitario-municipal de los aprovechamientos de corrientes fluviales convertía al agua en un elemento vital y un factor productivo dotado de un doble potencial. Es cierto que impulsó peligrosos conflictos intercomunitarios; pero no podemos olvidar que, al mismo tiempo, actuó como un potente aglutinador que reforzaba todo tipo de solidaridades verticales en el ámbito local. Así, el cruel enfrentamiento que tuvo como escenario al azud de Villalonga en 1402 cumplió la función de cohesionar los múltiples intereses de clase que coexistían en el seno de cada comunidad rural enfrentada por el agua del Serpis, haciendo perder centralidad al antagonismo esencial entre señor y vasallos ${ }^{27}$.

El objetivo central perseguido por los regantes valencianos siempre fue mantener la conflictividad dentro de unas cuotas asumibles, que no perturbasen en exceso la convivencia ni amenazasen con provocar el colapso del sistema hidráulico. Su propósito era contener los antagonismos en niveles bajos, mediante una normativa consensuada y el funcionamiento adecuado de tribunales locales. Se conseguía así, mediante organizaciones comunitarias específicas, canalizar «con éxito las necesidades cooperativas de los regantes», evitando el peligro que la conflictividad desbocada, resultante de primar otros objetivos, paralizase el desarrollo económico (Maass y Anderson, 2010: 40, 75-76).

Debemos aceptar que la coerción extrema, la corrupción oligárquica y las manifestaciones de furores violentos afectaron a las acequias valencianas. Pero acto seguido debe matizarse que fueron manifestaciones coyunturales muy espectaculares, que deben ser tenidas en cuenta, pero sin perder de vista que se trató de episodios nada prevalentes o poco significativos en un balance largoplacista. La idea fundamental a retener es que, en las relaciones entre usuarios del agua, la cooperación predominó estructuralmente, resultado de aplicar una normativa consensuada por parte de unos tribunales locales cuyo funcionamiento fue satisfactorio.

El análisis de los antagonismos hidráulicos es una temática compleja que no se resuelve mediante tópicos sublimadores que escondan los conflictos ni idealizando el funcionamiento de las instituciones encargadas de atajarlos. Tampoco con simplificaciones reduccionistas, contemplándolos como meras disputas por un caudal insuficiente, ya que las rivalidades también provenían de encharcamientos nocivos de aguas sobrantes, desperdicios malintencionados ocasionados por la competencia productiva, discrepancias sobre criterios de gestión, etcétera ${ }^{28}$. La vía de análisis más fecunda consiste —a mi entender- en conceptualizar ideas sobre antagonismos hidráulicos a partir de series de datos en una perspectiva muy amplia, territorial y cronológicamente, que incluya al conjunto del País Valenciano entre los siglos XIII y XIX. En este sentido, la conflictividad originada por los usos del agua no debe contemplarse como un estigma descalificador. El hecho que se mantuviese habitualmente dentro de unos parámetros relativamente bajos, así como las acertadas adaptaciones institucionales desarrolladas en respuesta a exacerbaciones puntuales de disputas ${ }^{29}$, muestran que las tensiones sufridas actuaron como un

\footnotetext{
${ }^{27}$ Castillo, 1997: 113-116. Esta intensa solidaridad local se percibe también en las pugnas jurídicas suscitadas en torno al agua, ya que fue habitual adoctrinar testigos para que declarasen en los tribunales aquello que resultara beneficioso para la comunidad rural a la que pertenecían (Cueco, 1965: 69; Glick, 2005: 358).

${ }_{28}$ No se obtiene luz en el análisis aplicando dicotomías drásticas como secano/regadío, hidráulica «andalusí» cooperativa versus hidráulica «feudal» conflictivista, divisiones tajantes vinculación/separación agua-tierra, etc. Tampoco ayuda resolver la cuestión acotar el análisis a los últimos siglos medievales, olvidando las tres centurias del Antiguo Régimen. Y poco aporta limitarnos a realizar descripciones de casos locales en la corta duración.

${ }^{29}$ La peligrosidad de los conflictos intercomunitarios por el agua impulsó a las organizaciones de regantes a buscar articularse con los poderes políticos capaces de ejercer un papel arbitral moderador de tensiones, en especial
} 
valioso estímulo impulsor de acertadas mutaciones organizativas, capaces de compensar la creciente presión sobre el recurso agua que se produjo al multiplicarse, entre los siglos XIII y XIX, la superficie beneficiada por el riego.

El gobierno y gestión de las aguas en las grandes huertas del País Valenciano se caracterizó por una positiva complejidad institucional, rasgo que debe achacarse a un doble motivo. En parte, al hecho de tratarse de un recurso natural fluyente susceptible de usos alternativos (riego, molinos, transporte fluvial, etc.) y consecutivos (aguas vivas y aguas muertas). ${ }^{30}$ Pero, sobre todo, debe atribuirse a las acertadas respuestas dadas a las dificultades específicas del medio físico, en especial la sincronía entre la marcada aridez estival que se sufría en el territorio con la acentuada reducción del caudal que llegaba por los ríos durante parte de la primavera y todo el verano. Dichos inconvenientes ecológicos no llegaron a disparar las tensiones más allá de lo que podían soportar las comunidades rurales implicadas, ni tampoco frenaron un más que notable desarrollo agrario basado en la expansión del regadío. En definitiva, la evidente conflictividad no se convirtió en la tragedia profetizada en su día por G. Hardin gracias a que se recondujo mediante sucesivas adaptaciones institucionales consensuadas en el marco local, dotando a las organizaciones de regantes de normas negociadas que resultaron muy flexibles y efectivas. Es por ello (no porque la conflictividad se mantuviese siempre dentro de unos niveles ínfimos) que las acequias valencianas merecen seguir siendo -justamente- consideradas un referente mundial exitoso de entidades comunitarias de gestión de recursos naturales (Ostrom, 2011).

\section{Referencias}

Alberola, A. (1994): El pantano de Tibi y el sistema de riegos en la buerta de Alicante, Alicante, GilAlbert.

Barceló, M. (1988): La arqueología extensiva y el estudio de la creación del espacio rural, en Barceló (ed.): Arqueología medieval. En las afueras del "medievalismo", Barcelona, Crítica, pp. 195-274.

Barceló, M. (1989): El diseño de espacios irrigados en al-Andalus: un enunciado de principios generales, en El agua en las zonas áridas..., Almería, I, pp. XV-XLXI.

Borrull, F.X. (1828): Discurso sobre la distribución de las aguas del Turia..., Valencia, Benito Monfort.

Bosch, R. (2012): Particions antigues i modernes així de temps de moros com de aprés..., Estudis d'Història Agrària, 24, 151-164.

Branchat, V. (1784-1786): Tratado de Derechos y Regalías que corresponden al Real Patrimonio del Reyno de Valencia, 3 vols., Valencia, Monfort.

Burriel, E. (1971): la Huerta de Valencia. Zona Sur, Valencia, Alfons Magnànim.

Castillo, J. (1997): Els conflictes per l'aigua a la Safor medieval, Gandia, Alfons el Vell.

\footnotetext{
municipios y corona, cuya participación en el manejo del agua no debe contemplarse como mera injerencia perturbadora.

${ }^{30}$ Las vivas derivadas directamente de cauces fluviales y las muertas procedentes de filtraciones y escorrentías de riegos anteriores, como ocurría con especial intensidad en la huerta de Orihuela.
} 
Calatayud, S. (2000): Els sistemes de reg a les Riberes del Xúquer durant l'època contemporània (1800-1930): continuïtat i canvi, en Furió\&Lairón (eds.): L’espai de l'aigua..., Valencia, Ayuntamiento Alzira-Universidad Valencia, pp. 275-306.

Calatayud, S. y Furió, A. (1992): El sistema de riegos en Sueca y la comunidad de regantes (Siglos XIII-XX), en Historia y constitución de las comunidades de regantes de las Riberas del Júcar (Valencia), Madrid, M.A.P.A.-I.R.Y.D.A, pp. 297-339.

Calatayud, S. y Garrido, S. (2012): Negociación de normas e intervención estatal en la gestión del regadío: la Acequia Real del Júcar a mediados del siglo XIX, Hispania, 240, 95-118.

Cavanilles, A.J. (1795-1797): Observaciones sobre la historia natural, geografía, agricultura, población y Frutos del Reyno de Valencia, 2 vols., Madrid, Imprenta Real.

Cueco, J.M. (1965): La Font de la Vall de Segó, Valencia, Ayuntamiento.

Chabret, A. (1888): Sagunto: su historia y sus monumentos, Barcelona, 2 vols., Ramírez.

Fairén, V. (1975): El Tribunal de las Aguas de Valencia y su proceso, Valencia, Caja Ahorros.

Ferrer V. (1995): Fusta transportada pels rius Xúquer i Túria als anys 1840-1860, en Ribes, V. (ed.), La industrialització de la zona de Xàtiva en el context valencià, Ayuntamiento Xàtiva, pp. 267-280.

Ferri, M. (1997): Reorganización de los riegos valencianos en el siglo XIX: las Ordenanzas liberales de la Provincia de Valencia (1835-1850), Áreas, 17, 77-89.

Ferri, M. (2002): Terratinents, camperols $i$ soldats. Regadiu i conflicte social al Camp de Morvedre, Valencia, Universidad.

Franquet, C. (1864): Ensayo sobre el origen, espiritu y progresos de la legislación de las aguas..., 2 vols., Madrid, Imprenta Ducazcal.

Furió, A. y L.P. Martínez (1994): Assuts i molins sobre el Xúquer en la Baixa Edat Mitjana, Actes IV Congrés d'Arqueologia Medieval Espanyola ("Societats en transició), Alicante, Generalitat, A.E.A.M. y Ayuntamiento de Alicante, 575-586.

Furió, A. y Martínez, L.P. (2000): De la hidràulica andalusí a la feudal: continuïtat i ruptura. L'Horta del Cent a l'Alzira medieval, en Furió\&Lairón (eds.): L'espai de l'aigua..., Valencia, Ayuntamiento Alzira\&Universidad Valencia, pp. 19-73.

García Edo, V. (1994): Derechos históricos de los pueblos de la Plana a las aguas del río Mijares, Castellón, Diputación.

Garrido, S. (2011): Las instituciones de riego en la España del Este. Una reflexión a la luz de la obra de Elinor Ostrom, Historia Agraria, 53, 13-42.

Giménez, P. (2008): Las transformaciones del paisaje valenciano en el siglo XVIII: una perspectiva geográfica, Valencia, Alfons Magnànim.

Giner Boira, V. (1988): El Tribunal de las Aguas de Valencia, Valencia, Tribunal Aguas. 
Giner Perepérez, F. (1992): Los riegos del Júcar en Cullera en la época foral, en Historia y constitución de las comunidades de regantes..., Madrid, M.A.P.A.-I.R.Y.D.A., pp. 345-368.

Glick, T.F. (1988): Regadio y sociedad en la Valencia medieval, Valencia, Del Cénia al Segura.

Glick, T.F. (2005): Regants contra feudals. Observacions sobre uns plets d'aigua a la Ribera del Xúquer (segle XV), Afers, 51, 357-368.

Gual, M. (1979): Estudio histórico-geográfico sobre la Acequia Real del Xúquer, Valencia, Alfons Magnànim.

Guía, L. (1984): Cortes del reinado de Felipe IV, II: Cortes valencianas de 1645, Valencia, Departamento Historia Moderna.

Guillén, G. (1905): El agua. Sus aplicaciones a la agricultura, Barcelona, Puig.

Guinot, E. (2005): Usos i conflictes de l'aigua, Afers, 51, 265-270.

Guinot, E. y Selma, S. (2002): Las acequias de la Plana de Castelló, Valencia, Conselleria Agricultura.

Hermosilla, J. (dir.) (2002-2009): Regadios Históricos Valencianos, 11 vols., Valencia, Generalitat,

Hermosilla, J. y Morales, A.J. (1993): El sistema de reg de Benaguasil, La Pobla de Vallbona i l'Eliana, Lauro, 7, 65-78.

Iborra, J.M. (1981): Realengo y señorío en el Camp de Morvedre, Sagunto, Caja Ahorros.

Jaubert de Passá, F.J. (1844): Canales de riego de Cataluña y Reino de Valencia, leyes y costumbres que los rigen; reglamentos y ordenanzas de sus principales acequias, 2 vols., Valencia, Monfort.

Lana, J.M. y Laborda, M. (2013): El anidamiento institucional y su dinámica histórica en comunidades rurales complejas. Dos estudios de caso (Navarra, siglos XIV-XX), Documentos Trabajo SEHA, 13_07.

Lemeunier, G. (1997): Drenaje y crecimiento agrícola en la España mediterránea (1500-1800), Áreas, 17, 31-41.

Llavata, V. (1981): Historia de la villa y baronía de la Pobla de Vallbona, Pobla Vallbona.

Maass, A. y Anderson, R.L. (2010): Los desiertos reverdecerán. Estudio comparativo de la gestión del riego en el Mediterráneo españoly el Oeste norteamericano, Valencia, Conselleria Cultura.

Madoz, P. (1982): Diccionario Geográfico-Estadístico-Histórico de Alicante, Castellón y V alencia, 2 vols., Valencia, Alfons Magnànim.

Mangue, I. (2000): Séquies i molins de València: la séquia de Rascanya, hidraulisme al marge esquerre del Túria, en Glick\&Guinot\&Martínez (eds.): Els molins hidräulics valencians..., Valencia, Alfons Magnànim, pp. 405-450.

Martínez Sanmartín L.P. (1993): La lluita per l'aigua com a factor de producció. Cap a un model conflictivista d'anàlisi dels sistemes hidràulics valencians, Afers, 15, 27-44. 
Mayans, G. (1976): Epistolario, V, Escritos Económicos, Oliva, Ayuntamiento.

Memorial Ajustado del pleyto que sigue la justicia y regimiento de la villa de Oliva..., Valencia, viuda González, 1754.

Nadault de Buffon (1843): Des canaux d'arrosage de l'Italie septentrionale dans leurs rapports avec ceux du midi de la France. Traité théorique et pratique des irrigations..., Paris, Garilian-Goeury.

Nieto, A. (1980): Estatutos de Riegos del Juzgado Privativo de Aguas de Rojales dispuestos por el Dr. Jerónimo Mingot..., Almoradí, Caja Rural Orihuela.

Ostrom, E. (2011): El gobierno de los bienes comunes. La evolución de las instituciones de acción colectiva, México, FCE-IIS.

Palerm, J. (2000): Organización social y agricultura de riego, Antología sobre pequeño riego, II, en Palerm y Saldaña, Organizaciones Autogestivas, Colegio de Postgraduados y Plaza y Valdés, pp. $13-30$

Pérez Medina, T.V. (1997b): Dinamismo y continuidad en los espacios hidráulicos de las comarcas del Vinalopó (1500-1836), en Agua y territorio..., Petrer, CEL, pp. 35-70.

Pérez Medina, T.V. (2005): Conflictes pels recursos hidràulics del riu Vinalopó als segles XIVXVIII, Afers, 51, 437-456.

Peris, T. (1992): Regadío, producción y poder en la Ribera del Xúquer. La Acequia Real de Alzira, 12581847, Valencia, C.OP.U.T. y Confederación Hidrográfica Júcar.

Peris, T. (1995): La Sèquia Reial del Xúquer (1258-1847). Sintesi històrica i aportacions documentals, Alzira, Germania.

Peris, T. (1997): La conflictividad hidráulica en el País Valenciano entre los siglos XIII y XVIII», Áreas, 17, 43-60.

Peris, T. (2000): «El regadiu de la Valldigna (segles XVI-XVIII», L'avenç, 5, 48-67.

Peris, T. (2001): L'escenari i els protagonistes, Alzira, Bromera.

Peris, T. (2002): Les jerarquies socials, Alzira, Bromera.

Peris, T. (2003a): La gestió bidràulica en la sèquia d'Escalona, Alcàntera, Ayuntamiento Castelló Ribera.

Peris, T. (2003b): La terra de l'arròs i les moreres, Alzira, Bromera.

Peris, T. (2008): El regadiu. Evolució, organització i transcendència socioeconòmica, en Giralt, E. (dir.): Història Agrària dels Països Catalans, III, Barcelona, F.C.R.I., pp. 125-144.

Peris, T. (2012a): Les qüestions per l'aigua al País Valencià durant l'etapa feudal: l'exemple dels molins, Estudis d'Història Agrària, 24, 251-268. 
Peris, T. (2012b): La molinería hidráulica en el territorio valenciano durante los siglos XIII-XIX, Investigaciones Geográficas, 57, 39-60.

Peris, T. (2014a): Consideraciones acerca de la "hidráulica feudal" desde la perspectiva de los molinos valencianos (siglos XIII-XIX)», Historia Agraria, en vías de publicación.

Peris, T. (2014b): Els molins d'aigua valencians (segles XIII-XIX), Valencia, Alfons Magnànim.

Román, I. (2000): El regadio de Vila-Real durante los siglos XIII-XV, Villarreal, Ayuntamiento.

Romero, J. y Peris, T. (1992): Usos, distribució i control de l'aigua, Geografia General dels Països Catalans, II, Barcelona, Enciclopèdia Catalana, pp. 186-277.

Sanchis Ibor, C. (2001): Regadiu i canvi ambiental en l'Albufera de València, Valencia, Departamento Geografía y Centre Valencià d'Estudis del Reg.

Sanchis, C. y J. Piqueras (2001): La conducció fluvial de fusta a València (segles XIII-XIX), Cuadernos de Geografia, 69-70, 195-214.

Vercher, S. (2005): Sobre les causes de la conflictivitat intermunicipal a la Ribera Baixa del Xúquer durant l'Antic Règim (segles XVI-XVII), Afers, 51, 417-435.

Verdú, F. (1739): Informe sobre el regadío de Alicante..., Alicante.

Villa de Albalat de la Ribera de Xúquer..., Albalat, Ayuntamiento, 2007. 